\title{
A survey to evaluate the association between blood lead level and blood pressure among workers employed in factory manufacturing lead acid-storage batteries
}

\author{
Kalahasthi RB, PhD *, Barman T, MPharm, Rajmohan HR, M.B.B.S, DNB (Occupational Health) \\ Regional Occupational Health Centre (Southern), Nirmal Bhavan, ICMR Complex, Kannamangala (Post), Devanahalli, \\ Bangalore-562110, Karnataka, India.
}

\begin{abstract}
Received: September 2012, Accepted: December 2013

Background: There are many controversies reported about the association between blood lead levels and blood pressure among lead exposed workers. Studies have suggested incorporating lifestyle factors along with blood lead levels. The present study aimed to evaluate the effect of lead exposure on blood pressure changes among lead exposed workers in contemplation of lifestyle factors.

Materials and methods: Study design is descriptive. Three hundred ninety one male lead exposed workers were enrolled. The subjects were categorized into four groups according to their blood lead levels by using quartile distribution. Blood lead levels were measured by using an atomic absorption spectrophotometer. Blood pressure was measured by using a standard mercury sphygmomanometer. Data were analyzed by using SPSS (Version 7.5).

Results: The mean systolic blood pressure in quartile-2 blood lead levels and the prevalence of hypertensive in quartile-4 blood lead levels were significantly increased as compared to quartile-1 blood lead levels. Multiple regression analysis found no significant association between blood pressure and blood lead levels among lead exposed workers. The lifestyle factors such as alcohol consumption, smoking, body mass index and chewing of tobacco products were significantly associated with blood pressure changes among lead exposed workers.

Conclusion: The findings of the present study showed that there was a significant association noticed between blood pressure and lifestyle factors.
\end{abstract}

Keywords: Lead, Workers, Blood Pressure

\section{Introduction}

Hazardous chemicals used in manufacturing of lead-batteries are lead oxide $\left(\mathrm{PbO}_{2}\right)$, spongy lead $(\mathrm{Pb})$ and sulfuric acid $\left(\mathrm{H}_{2} \mathrm{SO}_{4}\right)$. The workers engaged in those processes are exposed to $\mathrm{Pb}$ through inhalation, ingestion and dermal contact. Lead enters into the body of workers by inhalation, ingestion and dermal contact. After entry into the body, lead will be accumulated in erythrocytes, soft and mineralized tissue. Occupationally exposure to $\mathrm{Pb}$ has a higher risk of cardiovascular disease as compared to the general population (1) and predicted the left ventricular diastolic dysfunction and local arterial $^{*}$ stiffness (2). Acute exposure of $\mathrm{Pb}$ has elevated the arterial blood pressure due to disorder of intracellular calcium ions, increased activities of angiotensin-converting enzyme, Na (+), K (+)-ATPase, matrix metalloproteinase and decreased activity of

\footnotetext{
*Corresponding author: Ravibabu Kalahasthi, Regional Occupational Health Centre, Nirmal Bhavan, Bangalore, Karnataka, India.

Email: kalahasthi20012002@yahoo.co.in
} 
nitric oxide synthase (3-5). Occupational exposure to $\mathrm{Pb}$ had the dose response association between BLL and blood pressure changes in workers employed in galleries of mine (3), battery recycling (6), automobile (7), tile factory (8), apprentices in lead exposed plants (9), crystal glass (10) bus drivers (11), firearm instructors (12), exhaust battery storage (13), and crystal toy making (14). Some of the studies have reported the relation between blood lead and blood pressure in lead battery workers (15-17). Navaho et al. (18) have reported that the BLL had no clinically significant effect on blood pressure and suggested following up of lifestyle predictors to be evaluated. Therefore, in this study, we decided to find the correlation between BLL with blood pressure changes among workers employed in a lead battery factory with contemplation of lifestyle factors.

\section{Materials and Methods}

The present study was carried out in male lead exposed subjects engaged in a lead acidstorage battery manufacturing plant located in Tamil Nadu (India). Research design is a descriptive study. For this study, sample sizes of 391 male lead exposed subjects were obtained by using target population 400 , confidence level $99 \%$ and margin of error $1 \%$. The study subjects were categorized into four groups according to their BLL using quartile distribution. Informed consent was obtained from the subjects included in the study.

A pre-designed pro-forma was used to collect the information related to socio-demographic characteristics, personal habits like alcohol consumption, smoking, dietary pattern, chewing of tobacco products and details of occupational history. Body mass index (BMI) was calculated by using height and weight of each subject and expressed as $\mathrm{Kg} / \mathrm{m} 2$.

Three $\mathrm{ml}$ of venous whole blood was collected in heparinized vacutte from the workers and stored at $-20^{\circ} \mathrm{C}$ until taken for analysis. Two $\mathrm{ml}$ of blood were digested using ETHOS-D, milestone microwave system (Italy) with two $\mathrm{ml}$ of nitric acid $\left(\mathrm{HNO}_{3}\right)$ and $0.2 \mathrm{ml}$ of hydrogen peroxide $\left(\mathrm{H}_{2} \mathrm{O}_{2}\right)$ by maintaining power, temperature and duration of time. The digested samples were made up to five $\mathrm{ml}$ using triple distilled water and centrifuged. The concentration of lead in blood was measured by using an atomic absorption spectrophotometer (GBCAvanta P. Australia). A known concentration of lead standard solution was digested and analyzed to serve as internal quality control. The recovery rate of $20 \mu \mathrm{g} / \mathrm{dL}$ of the standard lead solution was found in $100 \%$ with $\%$ RSD at $<0.5$. The BLL was expressed as $\mu \mathrm{g} / \mathrm{dL}$.

Data were analyzed by using SPSS (version 7.5). The student-t test was used to compare the mean levels of blood lead, age, BMI, experience, systolic and diastolic blood pressure among lead exposed workers. A chisquare test was used to compare the proportion of alcohol consumption, smoking habits and prevalence of systolic and diastolic blood pressure among lead exposed workers. Stepwise multiple regression analysis was used to assess the effect of blood lead and lifestyle factors on blood pressure among lead exposed workers.

\section{Results}

Descriptive characteristics of lead exposed workers are presented in table 1 . The mean and standard deviation of blood lead levels, age, experience, BMI and proportions of alcohol consumption and smoking habits were reported in lead exposed workers. The 
mean blood lead levels of Q2, Q3 \& Q4 were significantly increased as compared to BLL of Q1. The means quartiles of blood-lead levels of Q1 to Q4 were ranged from15$44 \mu \mathrm{g} / \mathrm{dL}$. The proportions of smoking habits were not significantly associated. Alcohol consumption proportion in Q4 blood lead levels was significantly $(\mathrm{P}=0.048)$ associated as compared to the lowest quartile.

Table 1: Descriptive characteristics of lead exposed workers

\begin{tabular}{|c|c|c|c|c|c|}
\hline \multirow{2}{*}{ Characteristics } & \multirow{2}{*}{$\begin{array}{c}\text { Total } \\
(\mathrm{N}-391)\end{array}$} & \multicolumn{4}{|c|}{ Blood lead Quartile } \\
\hline & & $\begin{array}{l}\text { Quartile1 } \\
(\mathrm{N}=101)\end{array}$ & $\begin{array}{l}\text { Quartile } 2 \\
(\mathrm{~N}=107)\end{array}$ & $\begin{array}{c}\text { Quartile } 3 \\
(\mathrm{~N}=90)\end{array}$ & $\begin{array}{c}\text { Quartile } 4 \\
(\mathrm{~N}=93)\end{array}$ \\
\hline Blood lead levels $(\mu \mathrm{g} / \mathrm{dL})$ & $27.6 \pm 11.4$ & $15.1 \pm 1.3$ & $22.0 \pm 2.5$ & $31.3 \pm 3.1$ & $44.0 \pm 6.3$ \\
\hline Age(years) & $34.5 \pm 4.5$ & $35.5 \pm 3.4$ & $34.6 \pm 4.7$ & $35.1 \pm 4.5$ & $32.5 \pm 4.9$ \\
\hline Body mass index $(\mathrm{Kg} / \mathrm{m} 2)$ & $24.7 \pm 2.7$ & $24.9 \pm 2.4$ & $25 \pm 2.7$ & $24.8 \pm 2.6$ & $24.8 \pm 2.9$ \\
\hline Experience (Years) & $11.3 \pm 3.0$ & $12.4 \pm 1.9$ & $11.3 \pm 3.2$ & $11.4 \pm 2.8$ & $10.0 \pm 3.4$ \\
\hline \multicolumn{6}{|l|}{ Alcohol consumption (\%) } \\
\hline Yes & 37.0 & 31.0 & 29.0 & 45.0 & $46.0 *$ \\
\hline No & 63.0 & 69.0 & 71.0 & 55.0 & 54.0 \\
\hline \multicolumn{6}{|l|}{ Smoking habit (\%) } \\
\hline Yes & 19.0 & 15.0 & 19.0 & 23.0 & 22.0 \\
\hline No & 80.0 & 85.0 & 81.0 & 77.0 & 78.0 \\
\hline
\end{tabular}

$* \mathbf{P}<\mathbf{0 . 0 5}$

Table 2 shows the mean systolic and diastolic blood pressure and its prevalence of hypertension in lead exposed workers according to their BLL. Mean SBP in Quartile2 blood lead levels was significantly $(\mathrm{P}=0.020)$ increased as compared to the quartile1. The prevalence of systolic hypertension was significantly $(\mathrm{P}=0.032)$ increased in Q4 blood lead levels as compared to the Q1. The mean diastolic blood pressure and its prevalence of hypertension were not significantly associated in Q2, Q3 \& Q4 blood lead levels as compared to the Q1. A difference in blood-lead levels between the lowest Q1 and Q2, Q3 and Q4 was associated with a difference of 4.3, 1.5 and $3.0 \mathrm{mmHg}$ in SBP and $2.2,1.0 \& 1.0 \mathrm{mmHg}$ in DBP.

Table 2: Distribution of blood pressure-related variables in lead exposed workers

\begin{tabular}{|c|c|c|c|c|c|}
\hline \multirow[b]{2}{*}{ Characteristics } & \multirow[b]{2}{*}{$\begin{array}{c}\text { Total } \\
(\mathrm{N}-391)\end{array}$} & \multicolumn{4}{|c|}{ Blood lead Quartile } \\
\hline & & $\begin{array}{l}\text { Quartile1 } \\
(\mathrm{N}=101)\end{array}$ & $\begin{array}{l}\text { Quartile } 2 \\
(\mathrm{~N}=107)\end{array}$ & $\begin{array}{c}\text { Quartile } 3 \\
(\mathrm{~N}=90)\end{array}$ & $\begin{array}{c}\text { Quartile } 4 \\
(\mathrm{~N}=93)\end{array}$ \\
\hline \multicolumn{6}{|l|}{ Blood pressure } \\
\hline Systolic (mmHg) & $125.7 \pm 13.8$ & $123.5 \pm 11.6$ & $127.8 \pm 14.7$ & $125.0 \pm 13.0$ & $126.5 \pm 15.5$ \\
\hline Diastolic( mmHg) & $79.5 \pm 7.8$ & $78.5 \pm 7.3$ & $80.7 \pm 8.0$ & $79.4 \pm 7.8$ & $79.4 \pm 7.9$ \\
\hline \multicolumn{6}{|l|}{ Hypertension (\%) } \\
\hline Systolic $\geq 140 \mathrm{mmHg}$ & 20.0 & 13.0 & 22.0 & 20.0 & $26.0 *$ \\
\hline Diastolic $\geq 90 \mathrm{mmHg}$ & 15.0 & 11.0 & 16.0 & 18.0 & 16.0 \\
\hline
\end{tabular}


Table 3 shows the multiple regression analysis of variables effect on the systolic and diastolic blood pressure among lead exposed workers. The variables, included in the regression model, were systolic (SBP) and diastolic (DBP) pressure used as dependent variables and age, alcohol consumption, BLL, BMI, experience, smoking and chewing of tobacco products were used as independent variables. The multiple regression analysis showed that the alcohol consumption influences $13 \%$ on SBP in Q1 BLL. In Q2, blood-lead levels in the alcohol consumption, BMI, smoking and chewing of tobacco products influenced the $20 \%$ on SBP. In Q4 BLL, the BMI and chewing of tobacco products were associated with $17 \%$ for SBP. Chewing of tobacco products influences $14 \%$ on DBP in Q2 BLL. BMI influences $9.1 \%$ on DBP with BLL of Q4.

Table 3: Un-standardized regression coefficients ( $\beta$ ), standard error (SE) and probability (P) for blood lead, systolic and diastolic pressure in lead exposed workers

\begin{tabular}{|c|c|c|c|c|c|c|c|c|c|c|c|c|}
\hline & \multicolumn{12}{|c|}{ Blood lead Quartile } \\
\hline & \multicolumn{3}{|c|}{$\begin{array}{l}\text { Quartile1 } \\
(\mathrm{N}=101)\end{array}$} & \multicolumn{3}{|c|}{$\begin{array}{l}\text { Quartile 2 } \\
(\mathrm{N}=107)\end{array}$} & \multicolumn{3}{|c|}{$\begin{array}{c}\text { Quartile } 3 \\
(\mathrm{~N}=90)\end{array}$} & \multicolumn{3}{|c|}{$\begin{array}{c}\text { Quartile } 4 \\
(\mathrm{~N}=93)\end{array}$} \\
\hline \multicolumn{13}{|c|}{ Systolic blood pressure $(\mathrm{mmHg})$} \\
\hline \multirow{2}{*}{$\mathrm{R}^{2}$} & \multicolumn{3}{|c|}{13} & \multicolumn{3}{|c|}{20} & \multicolumn{3}{|c|}{7} & \multicolumn{3}{|c|}{17} \\
\hline & $\beta$ & SE & $\mathrm{P}$ & $\beta$ & SE & $P$ & $\beta$ & SE & $P$ & $\beta$ & SE & $P$ \\
\hline Age(years) & \multicolumn{3}{|c|}{$0.447(0.367) 0.223$} & \multicolumn{3}{|c|}{$0.608(0.322) 0.062$} & \multicolumn{3}{|c|}{$0.510(0.373) 0.174$} & \multicolumn{3}{|c|}{$1.008(0.427) 0.965$} \\
\hline Alcohol & \multicolumn{3}{|c|}{$5.144(2.512) 0.043^{*}$} & \multicolumn{3}{|c|}{$8.547(2.958) 0.005^{*}$} & \multicolumn{3}{|c|}{$0.742(3.095) 0.811$} & \multicolumn{3}{|c|}{$5.079(3.408) 0.140$} \\
\hline $\mathrm{BLL}(\mu \mathrm{g} / \mathrm{dL})$ & \multicolumn{3}{|c|}{$1.618(0.900) 0.075$} & \multicolumn{3}{|c|}{$0.288(0.524) 0.584$} & \multicolumn{3}{|c|}{$0.254(0.452) 0.575$} & \multicolumn{3}{|c|}{$0.439(0.250) 0.083$} \\
\hline $\mathrm{BMI}\left(\mathrm{Kg} / \mathrm{m}^{2}\right)$ & \multicolumn{3}{|c|}{$0.365(0.481) 0.449$} & \multicolumn{3}{|c|}{$0.995(0.498) 0.048 *$} & \multicolumn{3}{|c|}{$0.834(0.551) 0.134$} & \multicolumn{3}{|c|}{$1.451(0.568) 0.012^{*}$} \\
\hline Exp(years) & \multicolumn{3}{|c|}{$0.784(0.646) 0.227$} & \multicolumn{3}{|c|}{$8.001(0.465) 0.861$} & \multicolumn{3}{|c|}{$7.001(0.577) 0.897$} & \multicolumn{3}{|c|}{$0.358(0.599) 0.551$} \\
\hline Smoking & \multicolumn{3}{|c|}{$5.238(3.549) 0.143$} & 9.307 & 3.531 & $0.010^{*}$ & 5.160 & 3.85 & 0.184 & 2.150 & $(4.059$ & 0.598 \\
\hline Tobacco chewing & 13.13 & $(6.87$ & 0.059 & 15.202 & $(5.48$ & $0.007 *$ & 3.065 & $(7.99$ & 0.702 & 9.220 & $(4.315)$ & $0.035 *$ \\
\hline & & & & stolic b & $\overline{\mathrm{od} \mathrm{pr}}$ & ssure $(\mathrm{mr}$ & & & & & & \\
\hline & & 8 & & & 14 & & & $\overline{8.6}$ & & & 9.1 & \\
\hline & $\beta$ & SE & $\mathrm{P}$ & $\beta$ & SE & $P$ & $\beta$ & SE & $P$ & $\beta$ & SE & $P$ \\
\hline Age(years) & 0.007 & 0.23 & 0.757 & 0.262 & $(0.18$ & 0.158 & 0.119 & $(0.22$ & 0.593 & 0.008 & $\overline{(0.228}$ & 0.712 \\
\hline Alcohol & 2.132 & 1.616 & 0.190 & 2.708 & $(1.68$ & 0.112 & 0.999 & (1.84 & 0.589 & 1.54 & (1.824 & 0.400 \\
\hline $\mathrm{BLL}(\mu \mathrm{g} / \mathrm{dL})$ & 0.823 & 0.57 & 0.158 & 0.223 & $(0.29$ & 0.458 & 0.470 & $(0.26$ & 0.085 & 0.16 & $(0.134$ & 0.233 \\
\hline $\mathrm{BMI}\left(\mathrm{Kg} / \mathrm{m}^{2}\right)$ & 0.137 & 0.30 & 0.659 & 0.418 & $(0.28$ & 0.144 & 0.390 & $(0.32$ & 0.238 & 0.638 & $(0.304)$ & $0.039 *$ \\
\hline Exp(years) & 0.55 & 0.415 & 0.186 & 0.121 & $(0.26$ & 0.227 & 0.008 & $(0.34$ & 0.806 & 0.001 & $(0.321$ & 0.953 \\
\hline Smoking & 4.380 & 2.28 & 0.058 & 5.238 & $(3.54$ & 0.649 & 2.047 & $(2.29$ & 0.375 & 0.995 & (2.173 & 0.648 \\
\hline Tobacco chewing & 3.707 & 4.42 & 0.404 & 7.591 & 3.131 & $0.017 *$ & 6.116 & $(4.42$ & 0.202 & $1.46^{\circ}$ & $(2.310$ & 0.527 \\
\hline
\end{tabular}

$* \mathbf{P}<\mathbf{0 . 0 5}$

\section{Discussion}

The present study aimed to assess the effect of lead exposure on blood pressure changes among workers employed in a lead battery factory with consideration of lifestyle factors. The mean SBP in Q2 and its prevalence of hypertension in Q4-blood-lead levels were significantly increased as compared to the lowest Q1 BLL. Multiple regressions analysis showed that lifestyle predictors such as alcohol consumption, smoking, body mass index and chewing of tobacco products were significantly associated with blood pressure 
changes, but the BLL did not serve as a good predictor of blood pressure changes among workers. The findings of this study were comparable with other studies reported as no association between BLL and blood pressure changes in workers exposed to $\mathrm{Pb}$ from lead battery factories was found (15-18). The significant association was noticed between blood pressure changes and blood lead levels in workers from galleries of mine (3), battery recycling (6), automobile workers (7), tile factory workers (8), apprentices in lead exposed plants (9), crystal glass (10) bus drivers (11), firearm instructors (12), exhaust battery storage (13), crystal toy making (14), The findings of the present study showed that the only lifestyle predictors such as alcohol consumption, smoking, body mass index and chewing of tobacco products were significantly associated with blood pressure changes in workers and there was no statistically significant association between blood lead levels and blood pressure.

\section{Conclusions}

Mean SBP in Q2 blood lead levels and its prevalence of hypertensive in Q4 blood lead levels significantly increased as compared to the Q1 BLL. The lifestyle factors such as alcohol consumption, smoking, body mass index and chewing of tobacco products were significantly associated with systolic and diastolic blood pressure changes among workers.

\section{Acknowledgement}

The authors would like to thank Dr P.K Nag, the Director at the National Institute of Occupational Health (Ahmadabad), for his encouragement and support. The authors are also grateful to V Sehar, NSM siddaiah and
$\mathrm{N}$ Thara for their technical assistance. Last, but not least, the authors are grateful to the workers who participated in the study.

\section{Conflict of interest: Non declared}

\section{References}

1. Kim KR, Lee SW, Paik NW, Choi K. Lowlevel lead exposure among South Korean lead workers, and estimates of associated risk of cardiovascular diseases. J Occup Environ Hyg 2008; 5(6):399-416.

2. Poreba R, Gac P, Poreba M, AntonowiczJuchniewicz J, Andrzejak R. Relationship between occupational exposure to lead and local arterial stiffness and left ventricular diastolic function in individuals with arterial hypertension. Toxicol Appl Pharmacol 2011; 254(3):342-8.

3. Zeqiri N, Zeqiri S, Skenderaj S. Blood pressure evaluation at the workers exposed to lead. Med Arh 2012; 66(2):92-3.

4. Simoes MR, Ribeiro Junior RF, Vescovi MV, de Jesus HC, Padilha AS, Stefanon I, et. al. Acute lead exposure increases arterial pressure: role of the renin-angiotensin system. PLoS One 2011; 6(4):e18730.

5. Fiorim J, Ribeiro Junior RF, Silveira EA, Padilha AS, Vescovi MV, de Jesus HC et al. Low-level lead exposure increases systolic arterial pressure and endothelium-derived vasodilator factors in rat aortas. PLoS One 2011; 6(2):e17117.

6. Sadeghniiat-Haghighi K, Bahaedini LS, Mehrdad R, Meysami AP, Chavoshi F, Soltani SH. The relationship between blood pressure and lead exposure in battery recycling workers. J Biol Sci 2011; 11(7):454-8.

7. Dongre NN, Suryakar AN, Patil AJ, Ambekar JG, Rathi DB. Biochemical effects of lead exposure on systolic \& diastolic blood pressure, heme biosynthesis and hematological parameters in automobile workers of north karnataka (India). Indian J Clin Biochem 2011; 26(4):400-6.

8. Balali-Mood M, Shademanfar S, Rastegar Moghadam J, Afshari R, Namaei Ghassemi M, Allah Nemati H, et al. Occupational lead poisoning in workers of traditional tile 
factories in Mashhad, Northeast of Iran. Int J Occup Environ Med 2010; 1(1):29-38.

9. Pala K, Turkkan A, Gucer S, Osman E, Aytekin H. Occupational lead exposure: blood lead levels of apprentices in Bursa, Turkey. Ind Health 2009; 47(1):97-102.

10. Doroszko A, Skoczynska A, Drozdz K, Kreczynska B. Risk of cardiovascular diseases in lead-exposed workers of crystal glassworks. Part 11. Lead impact on the cardiovascular system based on ultrasound assessment of carotid arteries, alectrocardiograms and ankle-brachial index. Med Pr 2008; 59(5):355-63.

11. Kaewboonchoo O, Saleekul S, Powwattana A, Kawai T. Blood lead level and blood pressure of bus drivers in Bangkok, Thailand. Ind Health 2007; 45(4):590-4.

12. Di Lorenzo L, Borraccia V, Corfiati M, Mantineo GA, Caciari T, Marino M, et.al. Lead exposure in firearms instructors of the Italian State Police. Med Lav 2010; 101(1):30-7.

13. Fenga C, Cacciola A, Martino LB, Calderaro SR, Di Nola C, Verzera A, et al. Relationship of blood lead levels to blood pressure in exhaust battery storage workers. Ind Health 2006; 44(2):304-9.

14. Nomiyama K, Nomiyama H, Liu SJ, Tao
YX, Nomiyama T, Omae K. Lead induced increase of blood pressure in female lead workers. Occup Environ Med 2002; 59(11):734-8.

15. Tepper A, Mueller C, Singal M, Sagar K. Blood pressure, left ventricular mass and lead exposure in battery manufacturing workers. Am J Ind Med 2001; 40(1):63-72.

16. Ehrlich R, Robins T, Jordaan E, Miller S, Mbuli S, Selby P, et al. Lead absorption and renal dysfunction in a South African battery factory. Occup Environ Med 1998; 55(7):453-60.

17. Wu TN, Shen CY, Ko KN, Guu CF, Gau HJ, Lai JS, et.al. Occupational lead exposure and blood pressure. Int J Epidemiol, 1996; 25(4):791-6.

18. Navah U, Froom P, Kristal-Boneh E, Moschovitch B, Ribak J. Relationship of blood lead levels to blood pressure in battery workers. Arch Environ Health 1996; 51(4):324-8.

19. The Seventh Report of the Joint National Committee on Prevention, Detection, Evaluation, and Treatment of High Blood Pressure, National High Blood Pressure Education Program. NIH Publication No. 045230, August 2004. 